\title{
Creatine target engagement with brain bioenergetics: a dose-ranging phosphorus-31 magnetic resonance spectroscopy study of adolescent females with SSRI-resistant depression
}

\author{
Douglas G. Kondo ${ }^{1} \cdot$ Lauren N. Forrest $^{2} \cdot$ Xianfeng Shi $^{1} \cdot$ Young-Hoon Sung ${ }^{1} \cdot$ \\ Tracy L. Hellem ${ }^{2} \cdot$ Rebekah S. Huber $^{2} \cdot$ Perry F. Renshaw ${ }^{1}$
}

Received: 27 November 2015 / Accepted: 3 February 2016 / Published online: 23 February 2016

(c) The Author(s) 2016. This article is published with open access at Springerlink.com

\begin{abstract}
Major depressive disorder (MDD) often begins during adolescence and is projected to become the leading cause of global disease burden by the year 2030 . Yet, approximately $40 \%$ of depressed adolescents fail to respond to standard antidepressant treatment with a selective serotonin reuptake inhibitor (SSRI). Converging evidence suggests that depression is related to brain mitochondrial dysfunction. Our previous studies of MDD in adult and adolescent females suggest that augmentation of SSRI pharmacotherapy with creatine monohydrate $(\mathrm{CM})$ may improve MDD outcomes. Neuroimaging with phosphorus-31 magnetic resonance spectroscopy $\left({ }^{31} \mathrm{P}-\mathrm{MRS}\right)$ can measure the high-energy phosphorus metabolites in vivo that reflect mitochondrial function. These include phosphocreatine ( $\mathrm{PCr}$ ), a substrate for the creatine kinase reaction that produces adenosine triphosphate. As part of the National Institute of Mental Health's experimental medicine initiative, we conducted a placebo-controlled doseranging study of adjunctive $\mathrm{CM}$ for adolescent females with SSRI-resistant MDD. Participants were randomized to receive placebo or CM 2, 4 or $10 \mathrm{~g}$ daily for 8 weeks. Pre- and post-treatment ${ }^{31} \mathrm{P}$-MRS scans were used to measure frontal lobe $\mathrm{PCr}$, to assess CM's target engagement with cerebral energy metabolism. Mean frontal lobe $\mathrm{PCr}$ increased by $4.6,4.1$ and $9.1 \%$ in the 2, 4 and $10 \mathrm{~g}$ groups,
\end{abstract}

Handling Editor: T. Wallimann and R. Harris.

Douglas G. Kondo

doug.kondo@hsc.utah.edu

1 Department of Psychiatry, University of Utah School of Medicine, 501 Chipeta Way, Salt Lake City, UT 84108, USA

2 The Brain Institute, 383 Colorow Drive, Salt Lake City, UT 84108, USA respectively; in the placebo group, $\mathrm{PCr}$ fell by $0.7 \%$. There was no group difference in adverse events, weight gain or serum creatinine. Regression analysis of $\mathrm{PCr}$ and depression scores across the entire sample showed that frontal lobe $\mathrm{PCr}$ was inversely correlated with depression scores $(p=0.02)$. These results suggest that $\mathrm{CM}$ achieves target engagement with brain bioenergetics and that the target is correlated with a clinical signal. Further study of CM as a treatment for adolescent females with SSRI-resistant MDD is warranted.

Keywords Creatine monohydrate $\cdot$ Phosphocreatine . Bioenergetics $\cdot$ Mitochondrial function $\cdot$ Adolescent depression · Women's health $\cdot$ Phosphorus-31 magnetic resonance spectroscopy

\section{Introduction}

Depressive disorders are the second leading cause of years lived with disability as of 2010 (Ferrari et al. 2013) and major depressive disorder (MDD) is projected to become the leading cause of global disease burden by 2030 (Lepine and Briley 2011). The onset of MDD commonly occurs during adolescence (Burke et al. 1991); in fact, MDD has a cumulative prevalence of $15-24 \%$ by age 19 (Lewinsohn et al. 1998; Merikangas et al. 2010) and results in significant disability and mortality in this age group (Birmaher et al. 2007). Selective serotonin reuptake inhibitors (SSRIs) are first-line medications for adolescents requiring MDD pharmacotherapy (Lewandowski et al. 2013); however, $\sim 40 \%$ of depressed adolescents fail to respond to initial treatment with an SSRI (Brent et al. 2008). These adolescents with treatment-resistant depression (TRD) are at risk for recurrence into adulthood, academic and social 
impairment and suicide (Zhou et al. 2014). The Treatment of SSRI-Resistant Depression in Adolescents (TORDIA) trial found that $\sim 60 \%$ of adolescents with TRD did not respond, when switched to a different SSRI or another antidepressant class (Brent et al. 2008). An alternative to switching medications is to introduce an adjunctive treatment, a strategy that has shown promise in the management of adults with TRD (Rush et al. 2009). Despite the public health importance of improving care for adolescent MDD, controlled clinical trials of augmentation strategies for adolescents with TRD are lacking.

During puberty (Angold et al. 1998), the prevalence of MDD among females rises to approximately twice that found in males (prevalence ratio 1.3-3.1; lifetime gender ratio 2.1) (Kuehner 2003), a finding that is robust to epidemiologic sampling across continents and cultures (Seedat et al. 2009). Thus, female adolescents are affected by MDD at twice the rate of males (Merikangas et al. 2010), a gender disparity that continues throughout the reproductive years (Bebbington et al. 2003; Robins and Regier 1991). Yet despite the evidence for gender-based differences in MDD pathophysiology (Hyde et al. 2008; Young and Korszun 2010) and treatment response (Yang et al. 2011; Bigos et al. 2009), little systematic research has focused on these empirical differences. In addition to the doubling of depression prevalence by the middle teenage years (Wade et al. 2002), girls with MDD have longer episodes and higher symptom severity compared to boys (McCauley et al. 1993) and a prolonged risk of recurrence compared with women whose first depressive episode occurs in adulthood (Kovacs 1996). Therefore, investigation of females with MDD during the critical 'window of vulnerability' that occurs in adolescence (Andersen and Teicher 2008; Hankin et al. 1998) provides a unique opportunity to reduce the burden of illness associated with depression.

Converging lines of evidence suggest that mitochondrial dysfunction and altered brain bioenergetics may contribute to the etiology of depression (Klinedinst and Regenold 2015; Gardner and Boles 2011). The neuroimaging technique phosphorus-31 magnetic resonance spectroscopy $\left({ }^{31} \mathrm{P}-\mathrm{MRS}\right)$ is the sole method for noninvasive, in vivo measurement of the high-energy phosphorus metabolites that reflect cerebral bioenergetics (Agarwal et al. 2010; Kondo et al. 2011a; Zhu et al. 2009). These include phosphocreatine $(\mathrm{PCr})$, beta-nucleoside triphosphate $(\beta-\mathrm{NTP}$; largely adenosine triphosphate, ATP) and inorganic phosphate (Pi) (Iosifescu et al. 2008). PCr is the substrate reservoir for the creatine kinase reaction (Wallimann et al. 1992; Jeong et al. 2011). In mitochondria, this reaction reversibly converts $\mathrm{PCr}$ into ATP + creatine in a 1:1 molar ratio (Brosnan and Brosnan 2007; Wallimann et al. 2011). Neuronal energy demands are met through a shift in reaction equilibrium, which is designed to maintain brain ATP concentrations constant (Andres et al. 2008; Schlattner et al. 2006).

Our previous translational studies of MDD reveal a pattern in baseline/pre-treatment ${ }^{31} \mathrm{P}-\mathrm{MRS}$ metabolites, in subjects who later respond to treatment in a clinical trial setting: increased PCr (Iosifescu et al. 2008) and decreased $\beta$-NTP (Renshaw et al. 2001). The pattern is more common in females (Renshaw et al. 2001); this fact, when combined with the evidence for gender dimorphism in frontal lobe $\mathrm{PCr}$ and Pi in healthy females (Riehemann et al. 1999), suggested that it might be possible to target bioenergetic metabolism in the development of novel treatments for females with MDD. To investigate this, we first sought to determine whether the concentration of ${ }^{31} \mathrm{P}-\mathrm{MRS}$ metabolites in brain could be modified by administration of creatine monohydrate $(\mathrm{CM})$. In a placebo-controlled study of healthy adults, we found that cerebral PCr and Pi increased and $\beta$-NTP decreased, in subjects receiving oral $C M$ versus placebo (Lyoo et al. 2003). This reproduced the alterations in ${ }^{31} \mathrm{P}$-MRS metabolites that predict responsiveness, in two distinct groups of MDD patients: (1) treatment-naïve subjects receiving initial pharmacotherapy with an SSRI (Renshaw et al. 2001); and (2) SSRI-resistant subjects who receive hormonal augmentation of their existing antidepressant (Iosifescu et al. 2008). These results raised the possibility that $\mathrm{CM}$ supplementation could be utilized to promote a 'treatment-responsive state' in both MDD and TRD. As an initial step, we recruited unmedicated female adults with MDD for a placebo-controlled trial of CM versus placebo, each added to the SSRI escitalopram. Compared with the SSRI + placebo group, subjects who received SSRI + creatine showed greater improvements in depression scores as early as week 2 of treatment (Lyoo et al. 2012), suggesting that adjunctive CM speeds response and increases remission in women with MDD. An open-label study of TRD in either MDD or BD also found that CM showed evidence of benefit in unipolar depression (Roitman et al. 2007). In parallel with our study of adult females, we also conducted a small-scale $(n=5)$ open-label study of CM in adolescent females with TRD who had failed to respond to a trial of the SSRI fluoxetine. ${ }^{31} \mathrm{P}$-MRS scans of the frontal lobe were acquired at baseline and repeated after 8 weeks of $\mathrm{CM}$ $4 \mathrm{~g}$ daily, with healthy control (HC) adolescent females scanned for comparison. The study's results included a mean $56 \%$ reduction in CDRS-R depression scores and an increase in $\mathrm{PCr}(p=0.02)$ in female adolescents with TRD compared to HC (Kondo et al. 2011b).

In an effort to accelerate treatment development in psychiatry, the U.S. National Institute of Mental Health (NIMH) recently announced the NIMH Experimental Medicine Initiative (Insel 2015). The initiative requires that NIMH-funded clinical trials shift their emphasis from tests of clinical efficacy, e.g., reduction in depression 
scores, to studies of disease mechanism (Insel and Gogtay 2014). This requires a translational demonstration of target engagement, where the 'target' is a molecular site or brain circuit linked to a mechanism of disease, the mechanism of action of the treatment under study, or both. The new trial format is designed to yield insight into how or for whom the targeted intervention works and potentially measures duration and dose-response. The data from clinical trials are then informative, regardless of a study's results: if the intervention engages the target and correlates with a signal in the clinical data, then development of the treatment-and those aimed at the same target-continues. If not, then the target's mechanistic relevance is ruled out, and the focus shifts to identifying new treatment targets. Based upon the preliminary studies described above, we received one in the initial wave of NIMH phased innovation awards (R21/ R33). This report presents the findings from the R21 proofof-principle study, a dose-ranging trial of $\mathrm{CM}$ for adolescent females with SSRI-resistant depression. The CM dose administered in our open-label study was $4 \mathrm{~g}$ daily, which was safe and well tolerated (Kondo et al. 2011b). We therefore tested one lower dose ( $2 \mathrm{~g}$ ) and one higher dose $(10 \mathrm{~g})$ in this study, in addition to placebo. The specified target of CM treatment was frontal lobe $\mathrm{PCr}$, because of its association with treatment response in prior studies of MDD and TRD. In fact, pre-treatment PCr predicts subsequent treatment 'responder' versus 'non-responder' status in TRD with an accuracy of $79 \%$ (83\% sensitivity; $75 \%$ specificity) (Iosifescu et al. 2008). Because our open-label adolescent data were collected in females, there were no extant placebo-controlled CM data in males with TRD and, perhaps, most importantly, because preclinical animal data suggest $\mathrm{CM}$ has antidepressant-like effects in female rats but is equivocal in males (Allen et al. 2010, 2015), the study's enrollment was limited to adolescent females. In addition, more recent data suggest CM's antidepressant-like effects are sex hormone dependent (Allen et al. 2015). The aims of this R21 were: to demonstrate that CM targets and alters brain energy metabolism in female adolescents with SSRI-resistant MDD in a dose-responsive manner, compared with placebo; and to determine the dose of CM offering the best combination of safety, tolerability and target engagement with mitochondrial function in these participants.

\section{Methods}

This was a single-site, placebo-controlled, dose-finding clinical trial of CM augmentation for adolescent females with SSRI-resistant MDD (ClinicalTrials.gov registry number: NCT01601210). The study was conducted under U.S. Food and Drug Administration Investigational New Drug
(IND) application \#104586 issued to Dr. Renshaw, and the University of Utah Institutional Review Board (IRB) approved this research. Written and verbal informed consent was obtained prior to performance of any researchrelated procedures: (1) parental permission and participant assent, for participants aged $<18$ years; or (2) participant consent, for participants $\geq$ age 18 years. An external Data Safety and Monitoring Board with authority to halt the study monitored the study's safety outcomes and risks to participants.

\section{Participants}

Participants were recruited through clinician referrals and IRB-approved advertising. The inclusion criteria were: females aged 13-20 years with a primary diagnosis of MDD; outpatient status; SSRI treatment for $\geq 8$ weeks at a dosage of $\geq 40 \mathrm{mg} /$ day fluoxetine or its equivalent; current Children's Depression Rating Scale-Revised (CDRS-R) (Poznanski and Mokros 1996; Mayes et al. 2010) raw score of $>40$ or Montgomery-Asberg Depression Rating Scale (MADRS) (Montgomery and Asberg 1979) score $>25$; and current Clinical Global Impression Scale-Severity (CGI-S) (Guy 1976) score $\geq 4$, indicating moderate severity of the current depressive episode. Diagnoses were established through administration of the Kiddie Schedule for Affective Disorders and Schizophrenia for School-Age Children-Present and Lifetime Version (K-SADS-PL) (Kaufman et al. 1997), or the Structured Clinical Interview for DSM-IV Axis I Disorders (SCID-CT) (First et al. 2007). All psychopharmacological treatments were stable for $\geq 30$ days at study entry, and participants were asked to hold their psychotropic medication regimens constant during the 8 weeks of randomized treatment. The study exclusion criteria were: pre-existing renal disease or proteinuria on baseline urinalysis testing; history of $\mathrm{CM}$ hypersensitivity or a previous failed therapeutic trial of $\mathrm{CM}$; concomitant treatment with antiepileptic or antipsychotic medications; current substance use disorder; unstable comorbid medical, neurological or psychiatric disorder; clinically significant suicidal or homicidal risk; positive pregnancy test or refusal to practice contraception or abstinence during the study; current breastfeeding; positive urine drug screen; known or suspected intellectual disability; and any contraindication to ${ }^{31} \mathrm{P}-\mathrm{MRS}$ imaging, e.g. ferromagnetic implant or claustrophobic anxiety. A complete blood count, comprehensive metabolic panel, urinalysis, urine drug screen and 12-lead electrocardiogram (ECG) were obtained at baseline, and testing was repeated at the conclusion of randomized treatment, to prospectively identify abnormalities associated with $\mathrm{CM}$ administration. Participants attended weekly clinic visits for the first 4 weeks and then bi-weekly visits through week 8 of treatment. At each visit, the CDRS-R and CGI-S were administered. 


\section{Phosphorus-31 magnetic resonance spectroscopy ( ${ }^{31}$ P-MRS) neuroimaging}

Neuroimaging was performed on a Siemens $3 \mathrm{~T}$ wholebody clinical scanner (Siemens Medical Solutions, Erlangen, Germany) that is FDA approved for clinical use. Participants first underwent a routine MRI protocol to acquire anatomic images in the axial and coronal planes. The protocol consists of a T1-weighted structural scan (MPRAGE), a double-echo T2-weighted scan and a fluid attenuated inversion recovery (FLAIR) scan. Examinations were performed with a quadrature radiofrequency coil (Clinical MR Solutions LLC, Brookfield, WI, USA). After localization, images were obtained using a T1-weighted, sagittal oriented 3D-magnetization prepared rapid gradient echo (MPRAGE) sequence (TR/TE/TI 2100/3.97/1100 ms, matrix size $256 \times 256$, FOV $256 \times 256 \mathrm{~mm}^{3}$, flip angle $12^{\circ}$, slice thickness $1.5 \mathrm{~mm}$, slab $192 \mathrm{~mm}$, bandwidth $190 \mathrm{~Hz} /$ pixel). Axial proton density and T2-weighted images were acquired to screen for structural abnormalities using 2D double-echo T2-weighted turbo spin echo (TSE) sequence (TR $7110 \mathrm{~ms}$, TE 28/84 ms, FOV $240 \times 210 \mathrm{~mm}$, slice thickness $3 \mathrm{~mm}$, flip $150^{\circ}$, bandwidth $179 \mathrm{~Hz} /$ pixel). A FLAIR sequence (TR/TE/TI 8000/90/2500 ms, slice thickness $5 \mathrm{~mm}$, FOV $240 \times 168 \mathrm{~mm}^{3}$, voxel size $0.8 \times 0.6 \times 5.0 \mathrm{~mm}$, bandwidth $200 \mathrm{~Hz} /$ pixel, turbo factor 13) was used to detect juxtacortical-cortical lesions. All anatomic MRI images were read by the University of Utah faculty radiologists.

${ }^{31} \mathrm{P}-\mathrm{MRS}$ data were acquired using a 3D-MRS sequence with elliptically weighted phase encoding, to minimize acquisition time, i.e., participant burden. The acquisition parameters were: data matrix size $8 \times 8 \times 8$, TR $2000 \mathrm{~ms}$, flip angle $90^{\circ}$ for hard RF pulse, Rx bandwidth $2.5 \mathrm{kHz}$, complex points 1024, readout duration $409 \mathrm{~ms}$, pre-acquisition delay $2.3 \mathrm{~ms}$, FOV $200 \times 200 \mathrm{~mm}^{2}$ and 16 number of excitations. Within the Siemens operator interface, the RF pulse-transmitted voltage was varied until the maximal phosphorus signal intensity within the volume of interest (VOI) was achieved. That voltage was deemed to be generating a $90^{\circ}$ flip angle. However due to field inhomogeneity, the true RF flip angle may vary across different brain tissues. Therefore to minimize the effects of RF field inhomogeneity, ${ }^{31} \mathrm{P}-\mathrm{MRS}$ results are expressed as the ratio of the individual metabolite concentrations to the total phosphate signal acquired from the VOI. Post-processing of ${ }^{31} \mathrm{P}-\mathrm{MRS}$ data was performed with the jMRUI software application (jMRUI v. 4.0, European Community) with the AMARES algorithm (Advanced Method for Accurate, Robust and Efficient Spectral fitting of MRS data with use of prior knowledge). Before fitting the free-induction-decay (FID) data, a Hamming filter was applied to reduce signal contamination from neighboring voxels, with apodization of $10 \mathrm{~Hz}$ line broadening. Fourier transformation, frequency shifts correction and zero-order/first order phase correction as well as baseline correction were applied. The structural image-processing tool FSL (FMRIB Software Library, Release 4.1, The University of Oxford) was used to estimate the gray matter (GM), white matter (WM) and cerebrospinal fluid (CSF) content of each voxel, to correct for the partial volume effects on the metabolite data. The MRS grid was positioned over the images in identical fashion for both scans. For each ${ }^{31} \mathrm{P}-\mathrm{MRS}$ metabolite, the peak area was calculated as a percentage of the total phosphorus (TP) signal acquired during the participant's scan. Figure 1 shows the region of interest in the frontal lobe slice and a representative ${ }^{31} \mathrm{P}-\mathrm{MRS}$ spectrum.

\section{Statistical analysis}

Group differences in demographic and baseline/pre-treatment variables among the four treatment groups were
Fig. 1 Frontal lobe region of interest for phosphorus-31 magnetic resonance spectroscopy scans and a representative 31P-MRS spectrum. NTP alpha, gamma and beta-nucleoside triphosphate, $\mathrm{PCr}$ phosphocreatine, $P D E$ phosphodiesters, $P i$ inorganic phosphate, $P M E$ phosphomonoesters
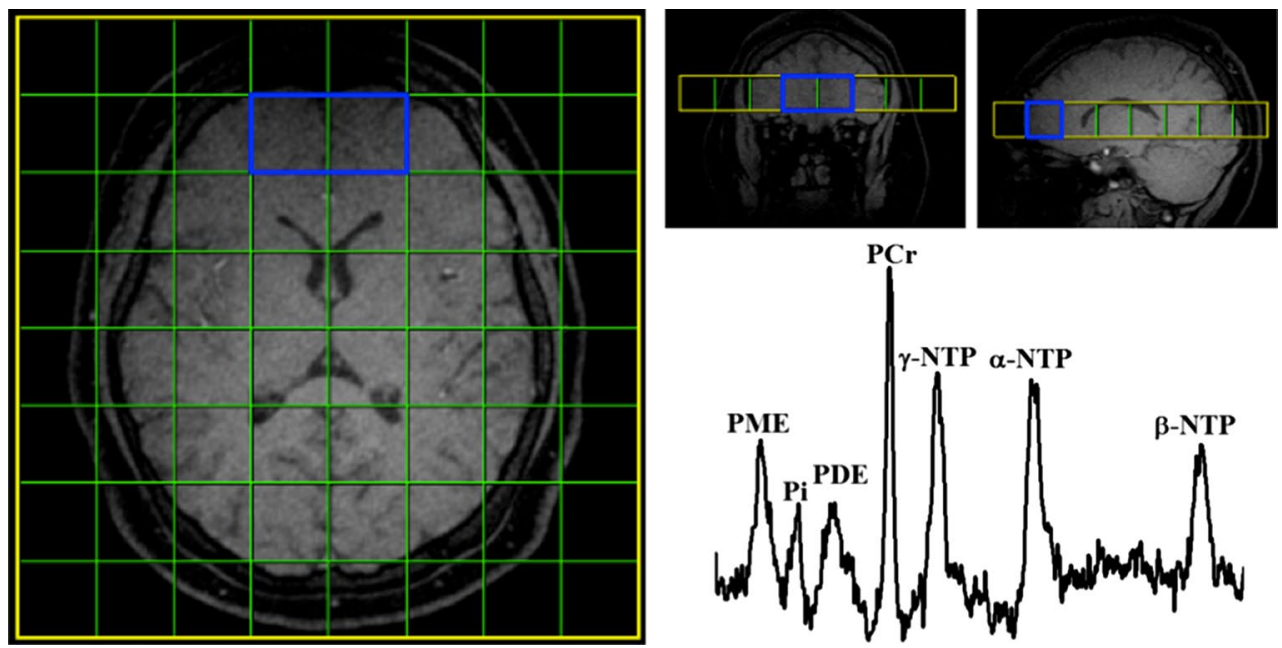
assessed using the analysis of variance (ANOVA) procedure. The linear mixed model (LMM) procedure was utilized for analysis of the primary outcome measure, frontal lobe ${ }^{31} \mathrm{P}-\mathrm{MRS} \mathrm{PCr}$, and the secondary outcome measure, CDRS-R depression scores (Bland and Altman 1994; Roy 2006; Cnaan et al. 1997). Because the neuroimaging and clinical measures were correlated, repeated measures data, a robust estimate of the variance, was obtained by implementing the vce(robust) option (Huber 1967; White 1980) in the statistical software Stata ${ }^{\circledR}$ for Linux, release 13 (StataCorp LP, College Station, TX, USA).

\section{Results}

As shown in Table 1 and displayed in the flow diagram in Fig. 2, we enrolled a total of $n=34$ participants. $N=45$ participants were formally assessed using the K-SADS-PL or SCID-CT, of which $n=11$ did not meet the diagnostic inclusion criteria. One participant met the criteria, but relocated 300 miles from Salt Lake City and, therefore, withdrew from further participation prior to her baseline/ pre-treatment scan. Complete data including two ${ }^{31} \mathrm{P}$-MRS scans were available for $n=28$ participants. Because the
Table 1 Participant baseline characteristics $(N=34)$

\begin{tabular}{|c|c|c|c|}
\hline & $\mathrm{N}$ & $\%$ & $p^{*}$ \\
\hline \multicolumn{4}{|l|}{ Demographic variables } \\
\hline \multicolumn{4}{|l|}{ Race } \\
\hline White & 33 & 97.1 & 0.39 \\
\hline African-American & 1 & 2.9 & \\
\hline \multicolumn{4}{|l|}{ Ethnicity } \\
\hline Not Hispanic or Latino & 32 & 94.1 & 0.60 \\
\hline Hispanic or Latino & 2 & 5.9 & \\
\hline \multicolumn{4}{|l|}{ Handedness } \\
\hline Right & 30 & 88.2 & 0.60 \\
\hline Left & 1 & 2.9 & \\
\hline \multirow[t]{2}{*}{ Missing } & 3 & 8.8 & \\
\hline & Mean & SD & \\
\hline Age (years) & 17.1 & 2.09 & 0.73 \\
\hline \multicolumn{4}{|l|}{ Clinical variables } \\
\hline Comorbid conditions & 1.33 & 0.85 & .046 \\
\hline \multicolumn{4}{|l|}{ Clinical Rating Scale Scores } \\
\hline CDRS-R & 57.52 & 6.29 & 0.48 \\
\hline MADRS & 26.85 & 5.68 & 0.14 \\
\hline \multirow[t]{2}{*}{ CGI-S } & 4.42 & 0.56 & 0.40 \\
\hline & $N$ & $\%$ & \\
\hline SSRI treatment & & & 0.29 \\
\hline Fluoxetine & 9 & 27.3 & \\
\hline Citalopram & 6 & 18.2 & \\
\hline Escitalopram & 4 & 12.1 & \\
\hline Sertraline & 14 & 42.4 & \\
\hline Concomitant medications & & & 0.48 \\
\hline Mixed amphetamine salts & 1 & 2.9 & \\
\hline Mirtazapine & 1 & 2.9 & \\
\hline Oral contraceptive & 2 & 5.9 & \\
\hline Bupropion & 2 & 5.9 & \\
\hline Vitamin D & 1 & 2.9 & \\
\hline Dropout & 5 & 15.0 & 0.52 \\
\hline
\end{tabular}

CDRS-R Children's Depression Rating Scale-Revised, CGI-S Clinical Global Impressions-Severity, $C$-SSRS Columbia-Suicide Severity Rating Scale, MADRS Montgomery-Asberg Depression Rating Scale * ANOVA 
Fig. 2 Participant flow diagram: screening, randomization and disposition of adolescent females with treatment-resistant major depressive disorder. $F U$ follow-up, SSRI selective serotonin reuptake inhibitor, $W C$ withdrew consent

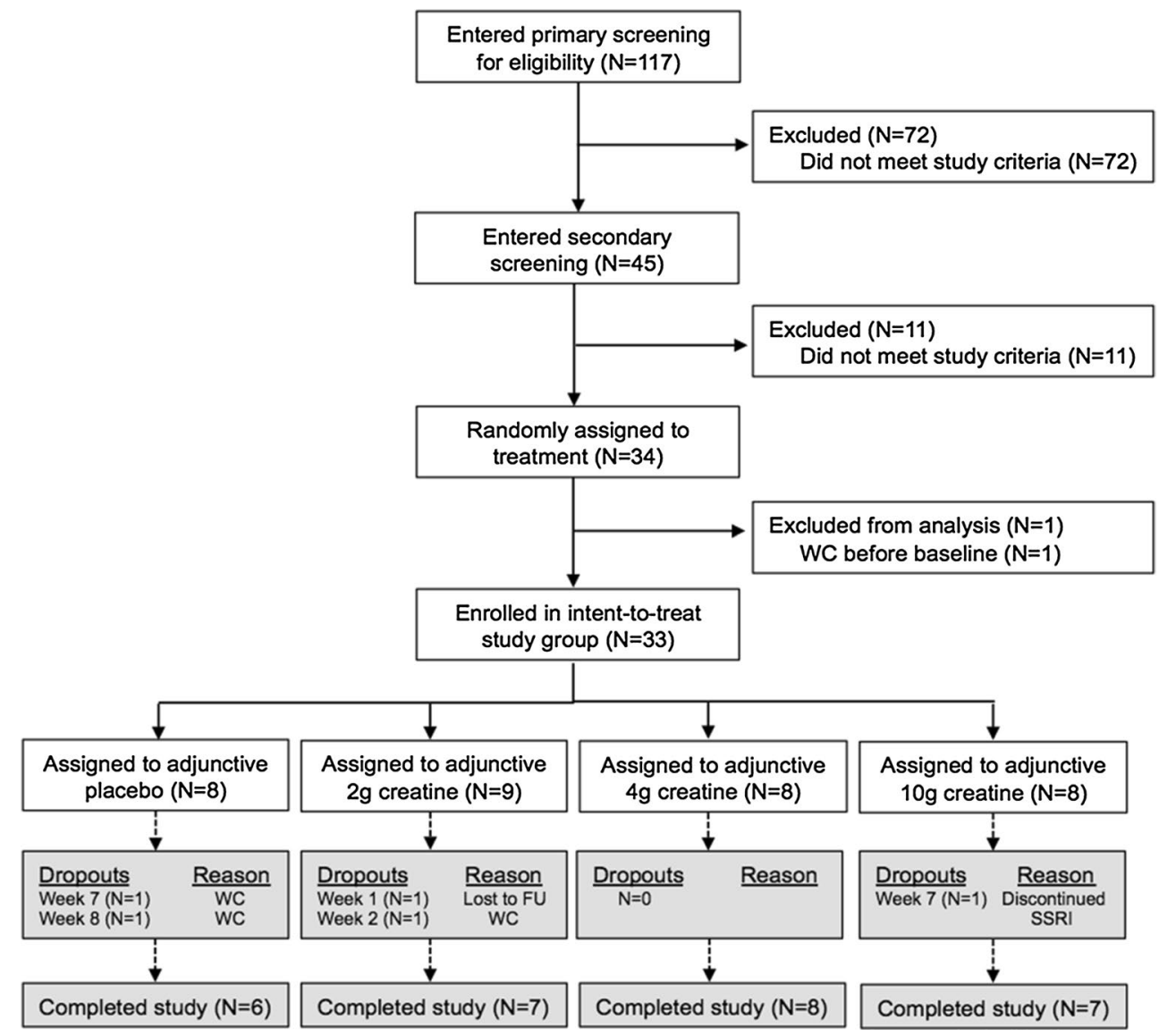

primary outcome measure of target engagement was frontal lobe PCr, statistical analyses were performed on the data collected from these 'protocol completers'. The sample included one African-American participant and two participants who self-identified as Hispanic or Latino.

Table 2 includes the baseline and week 8 outcomes, for the protocol completers who were randomized to each of four treatment conditions. The results of the ANOVA procedure indicated that there was no significant difference between groups at baseline, in terms of age $(p=0.38)$, pre-treatment frontal lobe $\mathrm{PCr}(p=0.75)$ or CDRS-R raw score at study entry $(p=0.51)$.

In terms of adverse events, gastrointestinal side effects were most commonly reported by participants in the placebo arm ( $n=4$ of $6 ; 67 \%)$. Participants experienced mild weight gain in all treatment conditions including placebo, as measured either in pounds (range 2.33-5.28 pounds; $p=0.75$ ) or in percent gained (range 1.7-3.9 \%; $p=0.64)$. Regarding safety, questions have been raised in the literature regarding CM's potential to impair renal function. Accordingly, participants' serum creatinine levels were measured prior to administration of study drug and repeated following 8 weeks of randomized treatment. We found no significant group difference in participants' mean serum creatinine, either at baseline (range 0.65-0.85 mg/
$\mathrm{dL} ; p=0.16$ ) or at week 8 (range $0.74-0.88 \mathrm{mg} / \mathrm{dL}$ ). In terms of the tolerability and acceptability of adjunctive CM, no subject withdrew from the study due to $\mathrm{CM}$-associated adverse events. Participants lost to follow-up included two who were unable to tolerate the baseline ${ }^{31} \mathrm{P}-\mathrm{MRS}$ scan and elected not to repeat it and the participant who relocated. No participant attempted suicide or was psychiatrically hospitalized, and there were no serious adverse events, as defined by the FDA. There were no unresolved treatmentemergent adverse events, abnormalities on laboratory testing or 12-lead ECGs.

The results of ${ }^{31} \mathrm{P}-\mathrm{MRS}$ showed a tendency for frontal lobe $\mathrm{PCr}$ to increase by 4.6, 4.1 and $9.1 \%$ in the CM 2, 4 and $10 \mathrm{~g}$ groups, respectively (Fig. 3; $p=0.69$ ). By contrast in the placebo group, frontal lobe $\mathrm{PCr}$ displayed a tendency to decrease by $0.7 \%$; frontal lobe $\mathrm{PCr}$ changes across all four treatment groups did not achieve statistical significance (Table $2 ; p=0.69$ ). We also found that only the $10 \mathrm{~g} \mathrm{CM}$ group demonstrated an increase in frontal lobe $\beta$-NTP: from baseline to week 8 , the observed difference in $\beta$-NTP was $-6.3 \%$ in the placebo group, $0 \%$ in the $2 \mathrm{~g}$ $\mathrm{CM}$ group, $-9.1 \%$ in the $4 \mathrm{~g} \mathrm{CM}$ group and $+3 \%$ in the 10 g CM group ( $p=0.47)$.

However as shown in Fig. 4, when the three active CM treatment groups were combined $(n=25)$ and compared 
Table 2 Protocol completer outcome measures: means and standard deviations

\begin{tabular}{|c|c|c|c|c|c|}
\hline Variable & Placebo & Creatine $2 \mathrm{~g}$ & Creatine $4 \mathrm{~g}$ & Creatine $10 \mathrm{~g}$ & $\begin{array}{l}p \text { value } \\
\text { ANOVA }\end{array}$ \\
\hline Number of participants & $N=6$ & $N=7$ & $N=8$ & $N=7$ & - \\
\hline Mean age (years) & $16.8(1.06)$ & $17.6(1.86)$ & $16.4(2.63)$ & $17.0(2.61)$ & 0.38 \\
\hline \multicolumn{6}{|l|}{$\mathrm{PCr} / \mathrm{TP}(N=28)$} \\
\hline Frontal lobe, baseline & $0.149(0.005)$ & $0.151(0.006)$ & $0.145(0.005)$ & $0.143(0.005)$ & 0.75 \\
\hline Frontal lobe, final & $0.148(0.004)$ & $0.158(0.004)$ & $0.151(0.003)$ & $0.156(0.003)$ & 0.32 \\
\hline Change $(\%)$ & -0.7 & +4.6 & +4.1 & +9.1 & 0.69 \\
\hline \multicolumn{6}{|l|}{$\beta-\mathrm{NTP} / \mathrm{TP}(N=28)$} \\
\hline Frontal lobe, baseline & $0.111(0.015)$ & $0.106(0.013)$ & $0.109(0.011)$ & $0.100(0.021)$ & 0.55 \\
\hline Frontal lobe, final & $0.104(0.008)$ & $0.106(0.015)$ & $0.099(0.001)$ & $0.103(0.012)$ & 0.86 \\
\hline Change (\%) & -6.3 & 0 & -9.1 & +3 & 0.47 \\
\hline \multicolumn{6}{|l|}{$\mathrm{PME} / \mathrm{TP}(N=28)$} \\
\hline Frontal lobe, baseline & $0.145(0.012)$ & $0.134(0.020)$ & $0.138(0.011)$ & $0.140(0.009)$ & 0.53 \\
\hline Frontal lobe, final & $0.132(0.011)$ & $0.138(0.013)$ & $0.145(0.014)$ & $0.143(0.008)$ & 0.28 \\
\hline Change (\%) & -9.0 & 3.0 & 5.1 & 2.1 & 0.72 \\
\hline \multicolumn{6}{|l|}{$\mathrm{PDE} / \mathrm{TP}(N=28)$} \\
\hline Frontal lobe, baseline & $0.163(0.022)$ & $0.167(0.017)$ & $0.169(0.007)$ & $0.167(0.019)$ & 0.93 \\
\hline Frontal lobe, final & $0.169(0.007)$ & $0.159(0.018)$ & $0.171(0.020)$ & $0.163(0.011)$ & 0.54 \\
\hline Change (\%) & 3.7 & -4.8 & 1.2 & 2.4 & 0.60 \\
\hline \multicolumn{6}{|l|}{ CDRS-R mean raw score } \\
\hline Baseline & $58.2(3.96)$ & $62.5(9.35)$ & $58.0(8.53)$ & $56.9(5.05)$ & 0.51 \\
\hline Final & $43.0(12.58)$ & $34.8(8.20)$ & $41.8(14.78)$ & $36.1(13.96)$ & 0.59 \\
\hline Change (\%) & -26 & -44 & -29 & -37 & - \\
\hline $\begin{array}{l}\text { Participants reporting } \\
\text { Gastrointestinal adverse events }\end{array}$ & $n=4 / 6$ & $n=2 / 7$ & $n=5 / 8$ & $n=4 / 7$ & - \\
\hline \multicolumn{6}{|l|}{ Weight gain } \\
\hline Pounds & $2.83(3.65)$ & $2.90(2.39)$ & $2.33(8.54)$ & $5.28(3.80)$ & 0.75 \\
\hline Percent & +1.8 & +2.2 & +1.7 & +3.9 & 0.64 \\
\hline \multicolumn{6}{|l|}{ Serum creatinine } \\
\hline Baseline (mg/dL) & $0.78(0.056)$ & $0.85(0.066)$ & $0.65(0.056)$ & $0.77(0.056)$ & 0.16 \\
\hline Final $(\mathrm{mg} / \mathrm{dL})$ & $0.79(0.051)$ & $0.84(0.062)$ & $0.74(0.057)$ & $0.88(0.053)$ & 0.32 \\
\hline
\end{tabular}

$C D R S-R$ Children's Depression Rating Scale, Revised, TP total phosphorus signal, $P C r$ phosphocreatine, $\beta$-NTP beta-nucleoside triphosphate, $P M E$ phosphomonoester, $P D E$ phosphodiester with the placebo group $(n=8)$ utilizing an LMM analysis of frontal lobe $\mathrm{PCr}$ versus CDRS-R scores, there was a significant negative correlation in the CM-treated group, i.e., higher frontal lobe PCr correlates with lower depression scale scores $(p=0.03)$; this relationship was not present in the placebo group. Furthermore, when the four treatment groups are combined and all frontal lobe $\mathrm{PCr}$ measurements are regressed versus all CDRS-R depression scores recorded at study scan visits, the negative correlation between frontal lobe $\mathrm{PCr}$ and CDRS-R scores becomes marginally more significant $(p=0.02)$, as shown in the left panel of Fig. 5. The right panel of Fig. 5 displays the individual scatter plots of the placebo, CM 2, 4 and $10 \mathrm{~g}$ groups. Visual inspection of the regression lines suggests that the 4 and $10 \mathrm{~g}$ treatment groups were responsible for the majority of the variance in the relationship between frontal lobe $\mathrm{PCr}$ and CDRS-R score. ${ }^{31} \mathrm{P}-\mathrm{MRS}$ can also be used to measure local concentrations of phosphomonoesters (PME) and phosphodiesters (PDE). PME consist of phospholipid membrane precursors, while PDE are phospholipid breakdown products. Although we found no significant between-group differences in post-treatment PME, visual inspection of the raw data shows that PME/ TP decreased by $9 \%$ in the placebo group, while PME/ TP was marginally increased in the three active CM treatment groups. While no conclusion can be drawn from this observation, it is perhaps notable that vesicular uptake of glutamate, a neurotransmitter implicated in mood disorders, may be regulated by PME and PCr (Xu et al. 1997). The results of the analysis of the mean percent tissue content of the VOI among the four treatment groups were as follows: GM pre-treatment ( $p=0.32$ ), GM post-treatment 


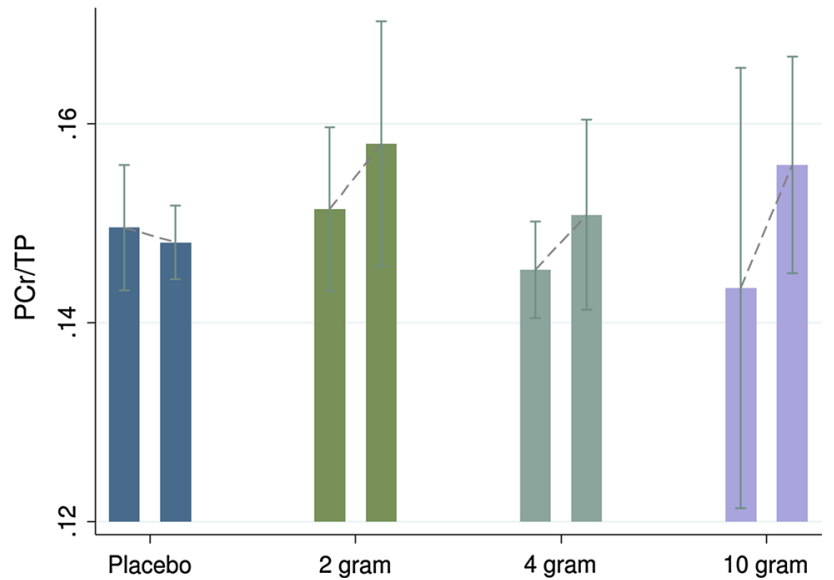

Fig. 3 Pre- versus post-treatment frontal lobe phosphocreatine ( $\mathrm{PCr} /$ $\mathrm{TP})$ in participants randomized to treatment with placebo or creatine 2,4 or 10 g daily $(N=28)$
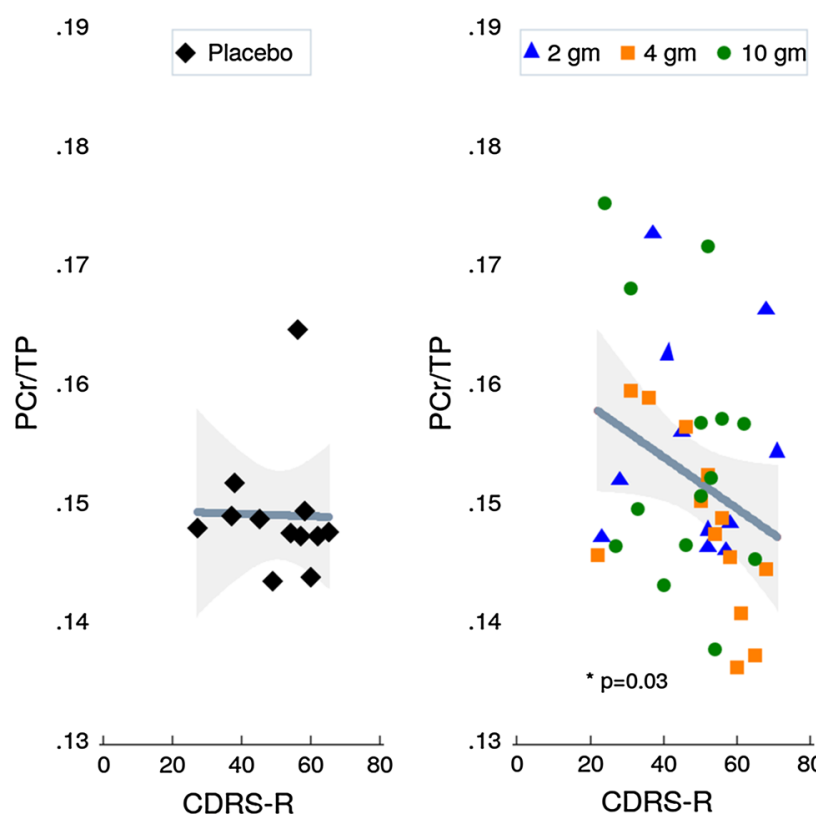

Fig. 4 Correlation between Children's Depression Rating ScaleRevised (CDRS-R) scores and frontal lobe phosphocreatine (PCr/TP) and in participants randomized to placebo (left) versus active treatment (right) with creatine 2,4 or $10 \mathrm{~g}(* p=0.03)$

$(p=0.73)$, WM pre-treatment $(p=0.15)$, WM post-treatment $(p=0.79)$, CSF pre-treatment $(p=0.82)$, CSF posttreatment $(p=0.92)$.

Finally, Fig. 6 displays the percent change in CDRS$\mathrm{R}$ clinical depression scores by treatment group, over the 8 weeks of randomized treatment. We did not find a statistically significant between-group difference in CDRS$\mathrm{R}$ scores at week $8(p=0.59)$, nor does the change in depression score appear to be dose-dependent. This may be related to the study sample size and the fact that participants randomized to the $2 \mathrm{~g}$ group had the highest mean CDRS-R score at baseline. Among the four groups, participants in the $2 \mathrm{~g}$ daily (mean CDRS-R $=34.8$ ) and $10 \mathrm{~g}$ daily (mean CDRS-R $=36.1$ ) groups no longer met the study's depression severity inclusion criterion (CDRS$\mathrm{R}>40$ ) at the end of treatment.

\section{Discussion}

The authors report the results of what is, to the best of our knowledge, the first ${ }^{31} \mathrm{P}-\mathrm{MRS}$ experimental medicine doseranging study of adjunctive CM for female adolescents with SSRI-resistant MDD. While our results diverge with those of a recent dose-ranging study of $\mathrm{CM}$ augmentation in adults with TRD (Nemets and Levine 2013), the outcome of interest in the present report was $\mathrm{PCr}$ measured with translational ${ }^{31} \mathrm{P}-\mathrm{MRS}$ neuroimaging. As found in our previous open-label study (Kondo et al. 2011b), augmentation of SSRI pharmacotherapy with CM was associated with increased frontal lobe PCr. Open treatment with $4 \mathrm{~g} \mathrm{CM}$ daily was associated with a $6.4 \%$ increase in the prior trial. In the present study, adjunctive 2, 4 and $10 \mathrm{~g}$ of CM daily for a total of 8 weeks was associated with tendencies toward increased frontal lobe $\mathrm{PCr}$ of 4.6, 4.1 and $9.1 \%$, respectively. By comparison, participants in the placebo group demonstrated a tendency toward decreased frontal lobe $\mathrm{PCr}$ of $0.7 \%$. In addition, target engagement with frontal lobe $\mathrm{PCr}$ was correlated with scores on the standard measure of depression severity employed in child psychiatry clinical trials, the CDRS-R (Figs. 3, 4). In terms of outcomes, participants randomized to the $2 \mathrm{~g}$ dose of CM appeared to show a tendency toward the most robust clinical response, as measured by CDRS-R scores (Fig. 6); however, this was not statistically significant $(p=0.59)$. This squares with what little is known regarding the response to placebo vs. active pharmacotherapy in adolescents with TRD. Zhou et al. (2014) performed a systematic review of adolescent TRD treatments and found that the only randomized, placebo-controlled trial in this population found no difference in the response rate to amitriptyline (76.9 \%) versus placebo (78.6\%) (Birmaher et al. 1998). The largest study of adolescent TRD conducted to date is the TORDIA clinical trial, which did not include a placebo arm among its four treatment conditions (Brent et al. 2008). Meanwhile, the NIMH has adopted the experimental medicine model for clinical research, moving away from tests of clinical efficacy to focus on disease mechanisms (Insel and Gogtay 2014; Insel 2015). The present dose-ranging study found that CM $10 \mathrm{~g}$ achieves target engagement with $\mathrm{PCr}$, while concomitant increases in adverse events such as gastrointestinal symptoms, weight gain or increased 
Fig. 5 Correlation between Children's Depression Rating Scale-Revised (CDRS-R) scores and frontal lobe phosphocreatine $(\mathrm{PCr} / \mathrm{TP})$ and in the entire sample $(p=0.02)$. Right panel scatter plot of the correlation between Children's Depression Rating Scale-Revised (CDRS$\mathrm{R})$ scores and frontal lobe $\mathrm{PCr} /$ $\mathrm{TP}$, displayed by treatment group: placebo, $2 \mathrm{~g}$ creatine, $4 \mathrm{~g}$ creatine and $10 \mathrm{~g}$ creatine. Left panel negative correlation between changes in Children's Depression Rating ScaleRevised (CDRS-R) scores and frontal lobe phosphocreatine/ total phosphorus signal ( $\mathrm{PCr} /$ TP) across all phosphorus magnetic resonance spectroscopy scans, i.e., lower depression scores correlate with higher $\mathrm{PCr} / \mathrm{TP}$ concentrations $(* p=0.02)$

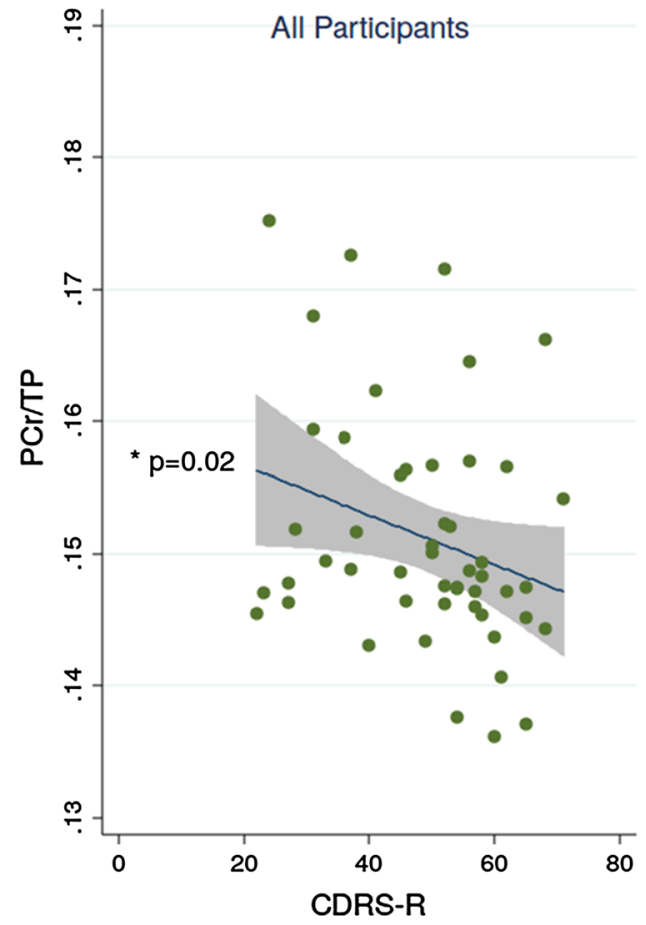

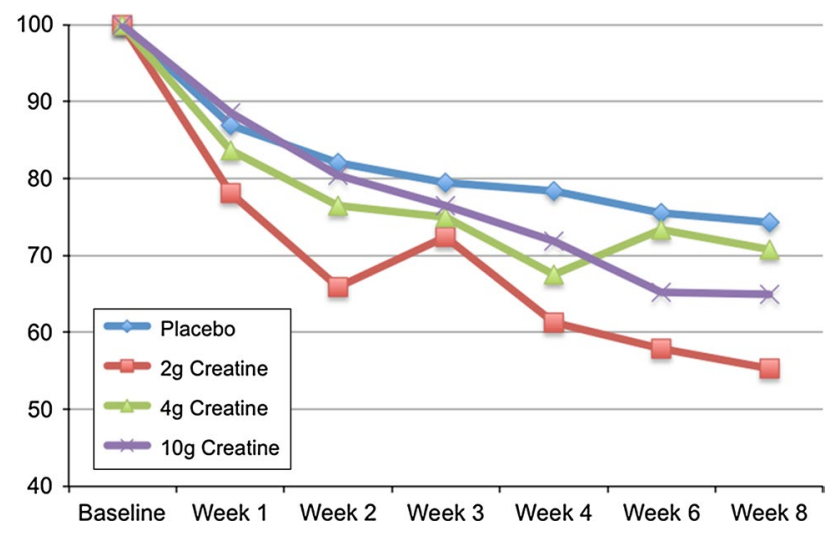

Fig. 6 Percent Change in Children's Depression Rating ScaleRevised (CDRS-R) scores from baseline to week 8, displayed by treatment group $(N=28)$

serum creatinine were not observed. Adding to the rationale for selecting the $10 \mathrm{~g}$ dose is the fact that pre-treatment $\mathrm{PCr}$ is an accurate predictor of treatment response in TRD (Iosifescu et al. 2008), and creatine's neuroprotective effect on brain bioenergetics is dose dependent, occurring at higher dosages (Atassi et al. 2010). Thus the relevance of the target, and its engagement by CM, appeared to be confirmed, and development of adjunctive $\mathrm{CM}$ as a treatment for TRD in adolescent females will continue. We have opened recruitment on the next phase of development, an NIMH-sponsored R33 placebo-controlled pilot study of CM $10 \mathrm{~g}$ for female adolescents with SSRI-resistant MDD, the results of which can be used to inform the design and implementation of a larger-scale efficacy study.

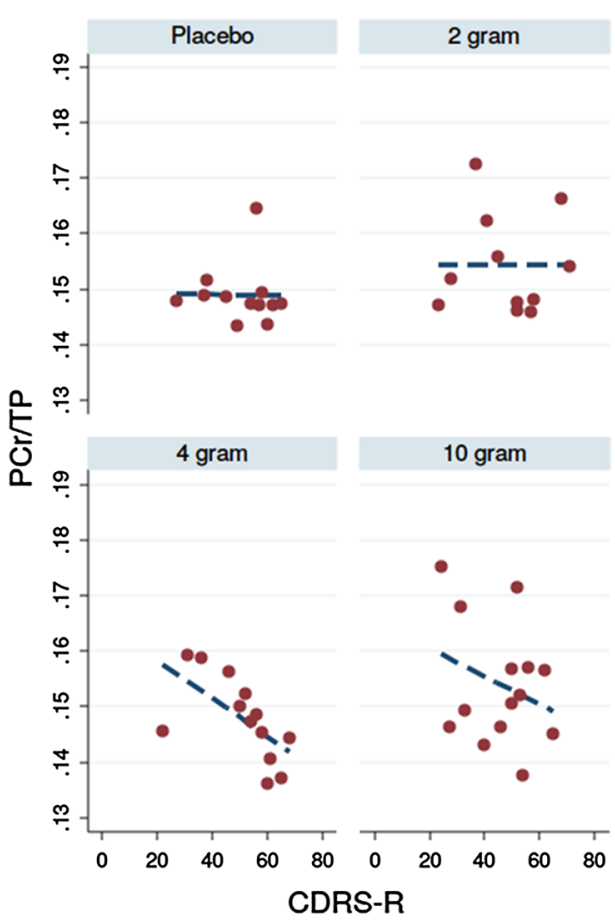

In addition to $\mathrm{PCr}$, another measure of mitochondrial function often reported in ${ }^{31} \mathrm{P}$-MRS studies of MDD is $\beta$-NTP, which is considered a proxy measure for the concentration of ATP. We did not find a discernible tendency in alterations in frontal lobe $\beta$-NTP in this study. However, there are important differences in the study samples, participant characteristics and VOI, between previous reports and the present study. For example, we previously reported that in healthy adult males, administration of $\mathrm{CM}$ for 14 days was associated with a significant decrease in the $\beta$-NTP resonance $(p=0.026)$ obtained from axial brain slice through the orbitofrontal and occipital cortices (Lyoo et al. 2003). We also found an $18 \%$ decrease in basal ganglia $\beta$-NTP $(p<0.03)$, in unmedicated adults with MDD versus healthy volunteers (Moore et al. 1997). This was followed by our report that basal ganglia $\beta$-NTP is $21 \%$ lower in MDD treatment responders versus nonresponders $(p=0.02)$ to SSRI fluoxetine (Renshaw et al. 2001). Another group reported decreased $\beta$-NTP in the frontal lobe ( $p=0.001)$, in a sample of $n=14$ adult men and women with MDD compared with $n=10$ healthy volunteers (Volz et al. 1998). The distinctions between these findings and the current report include the adolescent age group, an all-female sample and the fact that all of our participants were not only medicated, but treatment resistant at baseline, i.e., "non-responders." When added to the fact that the earlier studies were performed on $1.5 \mathrm{~T}$ scanning systems, these systematic differences in (1) magnet strength; (2) gender; (3) age range; (4) depression severity; (5) medication status; and (6) VOI, could plausibly account for the 
difference in findings with respect to $\beta$-NTP. Furthermore in their seminal ${ }^{31} \mathrm{P}-\mathrm{MRS}$ report, Kato et al. (1992) found no significant differences in $\beta$-NTP concentration among the following groups: MDD depressed, MDD euthymic, bipolar depressed, bipolar euthymic and healthy controls. In contrast, however, $\mathrm{PCr}$ was significantly decreased in severe versus mild MDD, and there was a non-significant tendency toward decreased $\mathrm{PCr}$ in bipolar depressed versus bipolar euthymic subjects (Kato et al. 1992).

MDD is a chronic, recurrent illness that frequently has its origins in adolescence (Burke et al. 1991). Unfortunately, the current antidepressants appear to possess limited efficacy in juvenile depression (Tsapakis et al. 2008), and adolescent MDD (Avenevoli et al. 2015) and TRD (Zhou et al. 2014) remain substantial public health concerns. The scope of the problem is highlighted by the fact that 350 million individuals suffer from depression worldwide (World Health Organization 2015). Depression costs are estimated at $\$ 200$ billion annually in the USA (Mrazek et al. 2014), surpassing the total spent on cancer or diabetes mellitus (Ionescu et al. 2015). Because the burden of MDD falls disproportionately on girls and women, successful development of interventions for female adolescents in this critical period of development could have a broad impact on public health.

The mitochondrial dysfunction associated with depression (Gardner and Boles 2011; Klinedinst and Regenold 2015) presents a tractable target for developing novel therapeutics and may also offer opportunities to improve the efficiency of drug development (Manji et al. 2012). In the context of the NIMH Experimental Medicine Initiative (Insel 2015), ${ }^{31} \mathrm{P}$-MRS is a translational tool capable of measuring 'target engagement' by quantifying the highenergy phosphorus-bearing neurometabolites involved in brain bioenergetics (Iosifescu and Renshaw 2003; Kato et al. 1992). One of these, $\mathrm{PCr}$, has been shown to predict treatment response in patients who have not responded to antidepressant pharmacotherapy (Iosifescu et al. 2008) and thus present a rational treatment target in TRD. This study joins prior reports from our group (Lyoo et al. 2003; Hellem et al. 2015; Kondo et al. 2011b) and others (Pan and Takahashi 2007; Bianchi et al. 2007) in providing in vivo evidence that oral $\mathrm{CM}$ administration achieves target engagement with brain bioenergetics and the creatine kinase system.

Numerous directions for further study of CM suggest themselves. For example, all protocol completers in the present study were offered a 6-month open-label extension of CM $4 \mathrm{~g}$ daily, the dose administered in our openlabel study. The rationale for this is twofold. Foremost is the obligation the investigators feel to offer participants randomized to placebo an opportunity to benefit from $\mathrm{CM}$ augmentation. Additionally, it is important to assess the durability of treatment effects and to collect long-term safety and tolerability data. The results of the 6-month extension study will be reported separately. Mechanistically, there is still much to be learned regarding CM's downstream effects in the brains of depressed individuals. A series of elegant experiments from the Rodrigues laboratory point toward an overlap in the neurobiological pathways involved in the antidepressant-like effect of CM in animal models and those of ketamine (Cunha et al. 2014, $2015 \mathrm{a}, \mathrm{b}, \mathrm{c})$. It is perhaps notable that ketamine is considered a 'rapid' antidepressant, and in our study of adult females with MDD, CM appeared to accelerate the antidepressant effects of the SSRI escitalopram (Lyoo et al. 2012). Based upon the gender dimorphism of creatine's effects in our rodent studies (Allen et al. 2010, 2012), there is the intriguing possibility of studying CM's antidepressant effect as monotherapy for untreated female adolescents with MDD. Given that antidepressants increase the risk of suicidal behavior in depressed youth (Hammad et al. 2006), this strategy may be worth exploring. Finally, in consideration of the converging evidence for sex-based differences in brain mitochondrial functioning (Demarest and McCarthy 2015), there may also be opportunities to explore genderspecific pharmacotherapies in depression. We have taken an initial step in that direction, with a study of CM supplementation to target depressive symptomatology in females with substance use disorders (Hellem et al. 2015). The gender dimorphism in rodent creatine kinase activity in brain has led investigators to conclude that females are more dependent on the system, between sexual maturity and senescence (Ramirez and Jimenez 2002). Recent data indicate that gender, sex hormones and metabolic status mediate the behavioral and neurochemical effects of $\mathrm{CM}$ supplementation. Specifically, combined CM and sex hormone treatment normalizes neuroplasticity-related gene expression in gonadectomized rats of both sexes and has an antidepressantlike effect in females (Allen et al. 2015). Given these findings and the evidence for sexual dimorphism in how brain mitochondria respond to both stress-depression paradigms and to subsequent treatment with SSRI medications (Adzic et al. 2013), further investigation of antidepressant strategies targeting brain bioenergetics in females with MDD is warranted.

This study's findings should be interpreted in light of several limitations. Chief among these is its small sample size, which limited our power to detect differences in the primary and secondary outcome measures between our four treatment groups. Two studies of adolescent depression implementing interventions other than CM, the TADS (March et al. 2004) and TORDIA (Brent et al. 2008) clinical trials, randomized $n=439$ and $n=334$ participants, respectively, to four different treatment groups. Furthermore, dose-ranging studies that employ conventional 
clinical outcomes must enroll $>100$ participants per dosing regimen tested (Erondu et al. 2006). Sample sizes of that magnitude are not feasible for translational neuroimaging studies and point toward the rationale for transitioning to 'target engagement' as the primary outcome measure for human subject research in the NIMH Experimental Medicine Initiative (Potter 2015). Another limitation is the low rate of creatine transporter (SLC6A8) expression in human brain endothelium (Lowe et al. 2015), which supports the suggestion that there is modest permeability for creatine at the blood-brain barrier (Braissant et al. 2001) and that de novo synthesis in glia may serve as the principal source of creatine in brain (Braissant et al. 2007; Tachikawa et al. 2004). Following intraperitoneal injection of creatine to rats, no significant increase in either creatine or $\mathrm{PCr}$ can be measured (Perasso et al. 2003). A recent report used established methods to estimate dietary creatine intake (Harris et al. 1997) and concluded that that diet does not influence brain creatine content and that the human brain is dependent on its own creatine biosynthesis (Yazigi Solis et al. 2014). While our own clinical trials (Lyoo et al. 2003; Hellem et al. 2015; Kondo et al. 2011b) and those of other investigators (Dechent et al. 1999; Atassi et al. 2010; Turner et al. 2015; Pan and Takahashi 2007) support the idea that CM administration alters creatine and/or PCr in brain, it is a limitation that all of these studies used a single methodmagnetic resonance spectroscopy-to measure subjects' brain chemistry. A frequent limitation of neuroimaging studies in psychiatry is the potential for confounding due to psychotropic medications, and the present report is no exception. Previous reports have documented the potential for antidepressants to alter neuroimaging results in females with MDD (Kaymak et al. 2009) and in adolescents (Singh and Chang 2012). Thus, it must be acknowledged that SSRI administration may have added noise to our ${ }^{31} \mathrm{P}$-MRS acquisitions, for which the signal-to-noise ratio is a critical source of variance. A final limitation that restricts the generalizability of our findings is that we studied only females. Future studies of CM in male adolescents with TRD may be warranted, but for ethical reasons we will need to await completion of at least one trial demonstrating CM's safety in adult males with depression.

In summary, we present the results of a double-blind, randomized, placebo-controlled dose-ranging clinical trial of adjunctive CM for female adolescents with SSRI-resistant MDD. Participants receiving $10 \mathrm{~g}$ appeared to show a greater degree of alteration in brain energy metabolism measured with repeated ${ }^{31} \mathrm{P}$-MRS neuroimaging, without concomitant differences in adverse events, tolerability or treatment acceptability. Furthermore, frontal lobe $\mathrm{PCr}$, the putative target of $\mathrm{CM}$ administration, demonstrated a correlation with clinical measures of depression across our study sample. Our results join converging lines of evidence from multiple scientific disciplines suggesting that $\mathrm{CM}$ may provide benefit in a range of brain-based disorders (Rae and Broer 2015; Allen 2012). We have now opened recruitment on a two-arm, placebo-controlled trial of CM $10 \mathrm{~g}$ for female adolescents with TRD. The results of that study will inform Go/No Go decision making regarding further development of CM and provide insight into the utility of adopting the experimental medicine framework for the discovery and validation of novel treatments in psychiatry.

Acknowledgments Creapure $^{\circledR}$ brand of creatine monohydrate was generously provided for the study by Dr. Heinz Ridder and AlzChem LLC. The authors thank Dr. Shelli Avenevoli of the United States National Institute of Mental Health for her valuable insights and support. In addition to the University of Utah, Dr. Kondo and Dr. Renshaw are employed by Rocky Mountain Mental Illness Research, Education and Clinical Center (MIRECC) at the George E. Wahlen Department of Veterans Affairs Medical Center. The views in this paper are those of the authors and do not necessarily represent the official policy or position of the United States Department of Veterans Affairs or the United States Government.

\section{Compliance with ethical standards}

Conflict of interest Dr. Renshaw and Dr. Kondo are co-inventors on United States and international patent applications that describe the use of creatine analogs to treat depressive disorders. The applications have been assigned to the University of Utah, which manages faculty conflicts of interest through its Office of Research Integrity and Compliance. Ms. Forrest, Dr. Shi, Dr. Sung, Dr. Hellem and Dr. Huber have no conflict of interest to declare.

Research involving human participants The University of Utah Institutional Review Board (IRB) approved this study. All procedures performed for this study were done in compliance with IRB regulations and in accordance with the ethical principles of the World Medical Association (WMA) 1964 Declaration of Helsinki and the subsequent revisions adopted by the WMA General Assembly in 1975, 1983, 1989, 1996, 2000, 2002, 2004, 2008 and 2013. This article does not contain or report any studies with animals performed by any of the authors.

Informed consent Informed consent was obtained from all individual participants included in this study. For minor participants, informed assent was obtained from the participant, as well as written parental permission from the participant's parent or legal guardian.

Open Access This article is distributed under the terms of the Creative Commons Attribution 4.0 International License (http://creativecommons.org/licenses/by/4.0/), which permits unrestricted use, distribution, and reproduction in any medium, provided you give appropriate credit to the original author(s) and the source, provide a link to the Creative Commons license, and indicate if changes were made.

\section{References}

Adzic M, Lukic I, Mitic M, Djordjevic J, Elakovic I, Djordjevic A, Krstic-Demonacos M, Matic G, Radojcic M (2013) Brain region- and sex-specific modulation of mitochondrial glucocorticoid receptor phosphorylation in fluoxetine treated stressed 
rats: effects on energy metabolism. Psychoneuroendocrinology 38:2914-2924

Agarwal N, Port JD, Bazzocchi M, Renshaw PF (2010) Update on the use of MR for assessment and diagnosis of psychiatric diseases. Radiology 255:23-41

Allen PJ (2012) Creatine metabolism and psychiatric disorders: does creatine supplementation have therapeutic value? Neurosci Biobehav Rev 36:1442-1462

Allen PJ, D'Anci KE, Kanarek RB, Renshaw PF (2010) Chronic creatine supplementation alters depression-like behavior in rodents in a sex-dependent manner. Neuropsychopharmacology 35:534-546

Allen PJ, D'Anci KE, Kanarek RB, Renshaw PF (2012) Sex-specific antidepressant effects of dietary creatine with and without sub-acute fluoxetine in rats. Pharmacol Biochem Behav 101(4):588-601

Allen PJ, DeBold JF, Rios M, Kanarek RB (2015) Chronic highdose creatine has opposing effects on depression-related gene expression and behavior in intact and sex hormone-treated gonadectomized male and female rats. Pharmacol Biochem Behav 130:22-33

Andersen SL, Teicher MH (2008) Stress, sensitive periods and maturational events in adolescent depression. Trends Neurosci 31:183-191

Andres RH, Ducray AD, Schlattner U, Wallimann T, Widmer HR (2008) Functions and effects of creatine in the central nervous system. Brain Res Bull 76:329-343

Angold A, Costello EJ, Worthman CM (1998) Puberty and depression: the roles of age, pubertal status and pubertal timing. Psychol Med 28:51-61

Atassi N, Ratai EM, Greenblatt DJ, Pulley D, Zhao Y, Bombardier J, Wallace S, Eckenrode J, Cudkowicz M, Dibernardo A (2010) A phase I, pharmacokinetic, dosage escalation study of creatine monohydrate in subjects with amyotrophic lateral sclerosis. Amyotroph Lateral Scler 11:508-513

Avenevoli S, Swendsen J, He JP, Burstein M, Merikangas KR (2015) Major depression in the national comorbidity survey-adolescent supplement: prevalence, correlates, and treatment. J Am Acad Child Adolesc Psychiatry 54(37-44):e32

Bebbington P, Dunn G, Jenkins R, Lewis G, Brugha T, Farrell M, Meltzer $H$ (2003) The influence of age and sex on the prevalence of depressive conditions: report from the National Survey of Psychiatric Morbidity. Int Rev Psychiatry 15:74-83

Bianchi MC, Tosetti M, Battini R, Leuzzi V, Alessandri MG, Carducci C, Antonozzi I, Cioni G (2007) Treatment monitoring of brain creatine deficiency syndromes: a 1H- and 31P-MR spectroscopy study. AJNR Am J Neuroradiol 28:548-554

Bigos KL, Pollock BG, Stankevich BA, Bies RR (2009) Sex differences in the pharmacokinetics and pharmacodynamics of antidepressants: an updated review. Gend Med 6:522-543

Birmaher B, Waterman GS, Ryan ND, Perel J, McNabb J, Balach L, Beaudry MB, Nasr FN, Karambelkar J, Elterich G, Quintana H, Williamson DE, Rao U (1998) Randomized, controlled trial of amitriptyline versus placebo for adolescents with "treatment-resistant" major depression. J Am Acad Child Adolesc Psychiatry 37:527-535

Birmaher B, Brent D, Bernet W, Bukstein O, Walter H, Benson RS, Chrisman A, Farchione T, Greenhill L, Hamilton J, Keable H, Kinlan J, Schoettle U, Stock S, Ptakowski KK, Medicus J (2007) Practice parameter for the assessment and treatment of children and adolescents with depressive disorders. J Am Acad Child Adolesc Psychiatry 46:1503-1526

Bland JM, Altman DG (1994) Correlation, regression, and repeated data. BMJ 308:896

Braissant O, Henry H, Loup M, Eilers B, Bachmann C (2001) Endogenous synthesis and transport of creatine in the rat brain: an in situ hybridization study. Mol Brain Res 86:193-201
Braissant O, Bachmann C, Henry H (2007) Expression and function of AGAT, GAMT and CT1 in the mammalian brain. Subcell Biochem 46:67-81

Brent D, Emslie G, Clarke G, Wagner KD, Asarnow JR, Keller M, Vitiello B, Ritz L, Iyengar S, Abebe K, Birmaher B, Ryan N, Kennard B, Hughes C, DeBar L, McCracken J, Strober M, Suddath R, Spirito A, Leonard H, Melhem N, Porta G, Onorato M, Zelazny J (2008) Switching to another SSRI or to venlafaxine with or without cognitive behavioral therapy for adolescents with SSRI-resistant depression: the TORDIA randomized controlled trial. JAMA 299:901-913

Brosnan JT, Brosnan ME (2007) Creatine: endogenous metabolite, dietary, and therapeutic supplement. Annu Rev Nutr 27:241-261

Burke KC, Burke JD Jr, Rae DS, Regier DA (1991) Comparing age at onset of major depression and other psychiatric disorders by birth cohorts in five US community populations. Arch Gen Psychiatry 48:789-795

Cnaan A, Laird NM, Slasor P (1997) Using the general linear mixed model to analyse unbalanced repeated measures and longitudinal data. Stat Med 16:2349-2380

Cunha MP, Budni J, Pazini FL, Oliveira A, Rosa JM, Lopes MW, Leal RB, Rodrigues AL (2014) Involvement of PKA, PKC, CAMK-II and MEK1/2 in the acute antidepressant-like effect of creatine in mice. Pharmacol Rep 66:653-659

Cunha MP, Budni J, Ludka FK, Pazini FL, Rosa JM, Oliveira Á, Lopes MW, Tasca CI, Leal RB, Rodrigues AL (2015a) Involvement of PI3K/Akt signaling pathway and its downstream intracellular targets in the antidepressant-like effect of creatine. Mol Neurobiol. doi:10.1007/s12035-015-9192-4

Cunha MP, Pazini FL, Ludka FK, Rosa JM, Oliveira A, Budni J, Ramos-Hryb AB, Lieberknecht V, Bettio LE, Martin-de-Saavedra MD, Lopez MG, Tasca CI, Rodrigues AL (2015b) The modulation of NMDA receptors and L-arginine/nitric oxide pathway is implicated in the anti-immobility effect of creatine in the tail suspension test. Amino Acids 47:795-811

Cunha MP, Pazini FL, Rosa JM, Ramos-Hryb AB, Oliveira A, Kaster MP, Rodrigues AL (2015c) Creatine, similarly to ketamine, affords antidepressant-like effects in the tail suspension test via adenosine $\mathrm{A}(1)$ and $\mathrm{A} 2 \mathrm{~A}$ receptor activation. Purinergic Signal 11:215-227

Dechent P, Pouwels PJ, Wilken B, Hanefeld F, Frahm J (1999) Increase of total creatine in human brain after oral supplementation of creatine-monohydrate. Am J Physiol 277:R698-R704

Demarest TG, McCarthy MM (2015) Sex differences in mitochondrial (dys)function: implications for neuroprotection. J Bioenerg Biomembr 47:173-188

Erondu N, Gantz I, Musser B, Suryawanshi S, Mallick M, Addy C, Cote J, Bray G, Fujioka K, Bays H, Hollander P, SanabriaBohorquez SM, Eng W, Langstrom B, Hargreaves RJ, Burns HD, Kanatani A, Fukami T, MacNeil DJ, Gottesdiener KM, Amatruda JM, Kaufman KD, Heymsfield SB (2006) Neuropeptide Y5 receptor antagonism does not induce clinically meaningful weight loss in overweight and obese adults. Cell Metab 4:275-282

Ferrari AJ, Charlson FJ, Norman RE, Patten SB, Freedman G, Murray CJ, Vos T, Whiteford HA (2013) Burden of depressive disorders by country, sex, age, and year: findings from the global burden of disease study 2010. PLoS Med 10:e1001547

First MB, Williams JB, Spitzer RL, Gibbon M (2007) Structured Clinical Interview for DSM-IV-TR Axis I Disorders, Clinical Trials Version (SCID-CT). Biometrics Research, New York State Psychiatric Institute, New York

Gardner A, Boles RG (2011) Beyond the serotonin hypothesis: mitochondria, inflammation and neurodegeneration in major depression and affective spectrum disorders. Prog Neuropsychopharmacol Bol Psychiatry 35:730-743 
Guy W (1976) ECDEU Assessment Manual for Psychopharmacology, Revised (Publication ADM 76-338), 2nd edn. U.S. Dept. of Health, Education, and Welfare, Public Health Service, Alcohol, Drug Abuse, and Mental Health Administration, National Institute of Mental Health, Psychopharmacology Research Branch, Division of Extramural Research Programs, Rockville, MD

Hammad TA, Laughren T, Racoosin J (2006) Suicidality in pediatric patients treated with antidepressant drugs. Arch Gen Psychiatry 63:332-339

Hankin BL, Abramson LY, Moffitt TE, Silva PA, McGee R, Angell KE (1998) Development of depression from preadolescence to young adulthood: emerging gender differences in a 10-year longitudinal study. J Abnorm Psychol 107:128-140

Harris RC, Lowe JA, Warnes K, Orme CE (1997) The concentration of creatine in meat, offal and commercial dog food. Res Vet Sci 62:58-62

Hellem TL, Sung YH, Shi XF, Pett MA, Latendresse G, Morgan J, Huber RS, Kuykendall D, Lundberg KJ, Renshaw PF (2015) Creatine as a novel treatment for depression in females using methamphetamine: a pilot study. J Dual Diagn 11(3-4):189-202

Huber PJ (1967) The behavior of maximum likelihood estimates under nonstandard conditions. In: Lecam L, Neyman J (eds) Proceedings of the fifth Berkeley symposium on mathematical statistics and probability. Volume 1: theory of statistics, vol 1. University of California Press, Berkeley and Los Angeles, CA USA, pp 221-233

Hyde JS, Mezulis AH, Abramson LY (2008) The ABCs of depression: integrating affective, biological, and cognitive models to explain the emergence of the gender difference in depression. Psychol Rev 115:291-313

Insel TR (2015) The NIMH experimental medicine initiative. World Psychiatry 14:151-153

Insel TR, Gogtay N (2014) National Institute of Mental Health clinical trials: new opportunities, new expectations. JAMA Psychiatry 71:745-746

Ionescu DF, Rosenbaum JF, Alpert JE (2015) Pharmacological approaches to the challenge of treatment-resistant depression. Dialogues Clin Neurosci 17:111-126

Iosifescu DV, Renshaw PE (2003) 31P-magnetic resonance spectroscopy and thyroid hormones in major depressive disorder: toward a bioenergetic mechanism in depression? Harv Rev Psychiatry 11:51-63

Iosifescu DV, Bolo NR, Nierenberg AA, Jensen JE, Fava M, Renshaw PF (2008) Brain bioenergetics and response to triiodothyronine augmentation in major depressive disorder. Biol Psychiatry 63:1127-1134

Jeong EK, Sung YH, Kim SE, Zuo C, Shi X, Mellon EA, Renshaw PF (2011) Measurement of creatine kinase reaction rate in human brain using magnetization transfer image-selected in vivo spectroscopy (MT-ISIS) and a volume (31) P/(1) H radiofrequency coil in a clinical 3-T MRI system. NMR Biomed 24:765-770

Kato T, Takahashi S, Shioiri T, Inubushi T (1992) Brain phosphorous metabolism in depressive disorders detected by phosphorus-31 magnetic resonance spectroscopy. J Affect Disord 26:223-230

Kaufman J, Birmaher B, Brent D, Rao U, Flynn C, Moreci P, Williamson D, Ryan N (1997) Schedule for Affective Disorders and Schizophrenia for School-Age Children-Present and Lifetime Version (K-SADS-PL): initial reliability and validity data. J Am Acad Child Adolesc Psychiatry 36:980-988

Kaymak SU, Demir B, Oguz KK, Senturk S, Ulug B (2009) Antidepressant effect detected on proton magnetic resonance spectroscopy in drug-naive female patients with first-episode major depression. Psychiatry Clin Neurosci 63:350-356

Klinedinst NJ, Regenold WT (2015) A mitochondrial bioenergetic basis of depression. J Bioenerg Biomembr 47:155-171
Kondo DG, Hellem TL, Sung YH, Kim N, Jeong EK, Delmastro KK, Shi X, Renshaw PF (2011a) Review: magnetic resonance spectroscopy studies of pediatric major depressive disorder. Depress Res Treat 2011:650450

Kondo DG, Sung YH, Hellem TL, Fiedler KK, Shi X, Jeong EK, Renshaw PF (2011b) Open-label adjunctive creatine for female adolescents with SSRI-resistant major depressive disorder: a 31-phosphorus magnetic resonance spectroscopy study. J Affect Disord 135:354-361

Kovacs M (1996) Presentation and course of major depressive disorder during childhood and later years of the life span. J Am Acad Child Adolesc Psychiatry 35:705-715

Kuehner C (2003) Gender differences in unipolar depression: an update of epidemiological findings and possible explanations. Acta Psychiatr Scand 108:163-174

Lepine JP, Briley M (2011) The increasing burden of depression. Neuropsychiatr Dis Treat 7:3-7

Lewandowski RE, Acri MC, Hoagwood KE, Olfson M, Clarke G, Gardner W, Scholle SH, Byron S, Kelleher K, Pincus HA, Frank S, Horwitz SM (2013) Evidence for the management of adolescent depression. Pediatrics 132:e996-e1009

Lewinsohn PM, Rohde P, Seeley JR (1998) Major depressive disorder in older adolescents: prevalence, risk factors, and clinical implications. Clin Psychol Rev 18:765-794

Lowe MT, Faull RL, Christie DL, Waldvogel HJ (2015) Distribution of the creatine transporter throughout the human brain reveals a spectrum of creatine transporter immunoreactivity. J Comp Neurol 523:699-725

Lyoo IK, Kong SW, Sung SM, Hirashima F, Parow A, Hennen J, Cohen BM, Renshaw PF (2003) Multinuclear magnetic resonance spectroscopy of high-energy phosphate metabolites in human brain following oral supplementation of creatine-monohydrate. Psychiatry Res 123:87-100

Lyoo IK, Yoon S, Kim TS, Hwang J, Kim JE, Won W, Bae S, Renshaw PF (2012) A randomized, double-blind placebo-controlled trial of oral creatine monohydrate augmentation for enhanced response to a selective serotonin reuptake inhibitor in women with major depressive disorder. Am J Psychiatry 169:937-945

Manji H, Kato T, Di Prospero NA, Ness S, Beal MF, Krams M, Chen G (2012) Impaired mitochondrial function in psychiatric disorders. Nat Rev Neurosci 13:293-307

March J, Silva S, Petrycki S, Curry J, Wells K, Fairbank J, Burns B, Domino M, McNulty S, Vitiello B, Severe J (2004) Fluoxetine, cognitive-behavioral therapy, and their combination for adolescents with depression: treatment for Adolescents With Depression Study (TADS) randomized controlled trial. JAMA 292:807-820

Mayes TL, Bernstein IH, Haley CL, Kennard BD, Emslie GJ (2010) Psychometric properties of the Children's Depression Rating Scale-Revised in adolescents. J Child Adolesc Psychopharmacol 20:513-516

McCauley E, Myers K, Mitchell J, Calderon R, Schloredt K, Treder R (1993) Depression in young people: initial presentation and clinical course. J Am Acad Child Adolesc Psychiatry 32:714-722

Merikangas KR, He JP, Burstein M, Swanson SA, Avenevoli S, Cui L, Benjet C, Georgiades K, Swendsen J (2010) Lifetime prevalence of mental disorders in U.S. adolescents: results from the National Comorbidity Survey Replication-Adolescent Supplement (NCSA). J Am Acad Child Adolesc Psychiatry 49:980-989

Montgomery SA, Asberg M (1979) A new depression scale designed to be sensitive to change. Br J Psychiatry 134:382-389

Moore CM, Christensen JD, Lafer B, Fava M, Renshaw PF (1997) Lower levels of nucleoside triphosphate in the basal ganglia of depressed subjects: a phosphorus-31 magnetic resonance spectroscopy study. Am J Psychiatry 154:116-118 
Mrazek DA, Hornberger JC, Altar CA, Degtiar I (2014) A review of the clinical, economic, and societal burden of treatment-resistant depression: 1996-2013. Psychiatr Serv 65:977-987

Nemets B, Levine J (2013) A pilot dose-finding clinical trial of creatine monohydrate augmentation to SSRIs/SNRIs/NASA antidepressant treatment in major depression. Int Clin Psychopharmacol 28:127-133

Pan JW, Takahashi K (2007) Cerebral energetic effects of creatine supplementation in humans. Am J Physiol Regul Integr Comp Physiol 292:R1745-R1750

Perasso L, Cupello A, Lunardi GL, Principato C, Gandolfo C, Balestrino M (2003) Kinetics of creatine in blood and brain after intraperitoneal injection in the rat. Brain Res 974:37-42

Potter WZ (2015) Optimizing early Go/No Go decisions in CNS drug development. Expert Rev Clin Pharmacol 8:155-157

Poznanski EO, Mokros HB (1996) Children's Depression Rating Scale, Revised (CDRS-R) manual. Western Psychological Services, Los Angeles

Rae CD, Broer S (2015) Creatine as a booster for human brain function. How might it work? Neurochem Int 89:249-259

Ramirez O, Jimenez E (2002) Sexual dimorphism in rat cerebrum and cerebellum: different patterns of catalytically active creatine kinase isoenzymes during postnatal development and aging. Int $\mathrm{J}$ Dev Neurosci 20:627-639

Renshaw PF, Parow AM, Hirashima F, Ke Y, Moore CM, Frederick Bde B, Fava M, Hennen J, Cohen BM (2001) Multinuclear magnetic resonance spectroscopy studies of brain purines in major depression. AJ Psychiatry 158:2048-2055

Riehemann S, Volz HP, Wenda B, Hubner G, Rossger G, Rzanny R, Sauer H (1999) Frontal lobe in vivo (31)P-MRS reveals gender differences in healthy controls, not in schizophrenics. NMR Biomed 12:483-489

Robins LN, Regier DA (1991) Psychiatric disorders in America: the epidemiologic catchment area study. Free Press, New York

Roitman S, Green T, Osher Y, Karni N, Levine J (2007) Creatine monohydrate in resistant depression: a preliminary study. Bipolar Disord 9:754-758

Roy A (2006) Estimating correlation coefficient between two variables with repeated observations using mixed effects model. Biom J 48:286-301

Rush AJ, Warden D, Wisniewski SR, Fava M, Trivedi MH, Gaynes BN, Nierenberg AA (2009) STAR*D: revising conventional wisdom. CNS Drugs 23:627-647

Schlattner U, Tokarska-Schlattner M, Wallimann T (2006) Mitochondrial creatine kinase in human health and disease. Biochim Biophys Acta (BBA) Mol Basis Dis 1762:164-180

Seedat S, Scott KM, Angermeyer MC, Berglund P, Bromet EJ, Brugha TS, Demyttenaere K, de Girolamo G, Haro JM, Jin R, Karam EG, Kovess-Masfety V, Levinson D, Medina Mora ME, Ono Y, Ormel J, Pennell BE, Posada-Villa J, Sampson NA, Williams D, Kessler RC (2009) Cross-national associations between gender and mental disorders in the World Health Organization World Mental Health Surveys. Arch Gen Psychiatry 66:785-795

Singh MK, Chang KD (2012) The neural effects of psychotropic medications in children and adolescents. Child Adolesc Psychiatr Clin N Am 21:753-771
Tachikawa M, Fukaya M, Terasaki T, Ohtsuki S, Watanabe M (2004) Distinct cellular expressions of creatine synthetic enzyme GAMT and creatine kinases uCK-Mi and CK-B suggest a novel neuron-glial relationship for brain energy homeostasis. Eur $\mathrm{J}$ Neurosci 20:144-160

Tsapakis EM, Soldani F, Tondo L, Baldessarini RJ (2008) Efficacy of antidepressants in juvenile depression: meta-analysis. Br J Psychiatry 193:10-17

Turner CE, Russell BR, Gant N (2015) Comparative quantification of dietary supplemented neural creatine concentrations with (1) H-MRS peak fitting and basis spectrum methods. Magn Reson Imaging 33:1163-1167

Volz HP, Rzanny R, Riehemann S, May S, Hegewald H, Preussler B, Hubner G, Kaiser WA, Sauer H (1998) 31P magnetic resonance spectroscopy in the frontal lobe of major depressed patients. Eur Arch Psychiatry Clin Neurosci 248:289-295

Wade TJ, Cairney J, Pevalin DJ (2002) Emergence of gender differences in depression during adolescence: national panel results from three countries. J Am Acad Child Adolesc Psychiatry 41:190-198

Wallimann T, Wyss M, Brdiczka D, Nicolay K, Eppenberger HM (1992) Intracellular compartmentation, structure and function of creatine kinase isoenzymes in tissues with high and fluctuating energy demands: the 'phosphocreatine circuit' for cellular energy homeostasis. Biochem J 281:21-40

Wallimann T, Tokarska-Schlattner M, Schlattner U (2011) The creatine kinase system and pleiotropic effects of creatine. Amino Acids 40:1271-1296

White H (1980) A Heteroskedasticity-consistent covariance matrix estimator and a direct test for heteroskedasticity. Econometrica 48:817-838

World Health Organization (2015) Depression Fact Sheet \#369. World Health Organization. http://www.who.int/mediacentre/factsheets/ fs 369/en/. Accessed 1 Nov 2015

Xu CJ, Kanfer JN, Klunk WE, Xiong Q, McClure RJ, Pettegrew JW (1997) Effect of phosphomonoesters, phosphodiesters, and phosphocreatine on glutamate uptake by synaptic vesicles. Mol Chem Neuropathol 32:89-99

Yang SJ, Kim SY, Stewart R, Kim JM, Shin IS, Jung SW, Lee MS, Jeong SH, Jun TY (2011) Gender differences in 12-week antidepressant treatment outcomes for a naturalistic secondary care cohort: the CRESCEND study. Psychiatry Res 189:82-90

Yazigi Solis M, de Salles PainelliV, Giannini Artioli G, Roschel H, Concepcion Otaduy M, Gualano B (2014) Brain creatine depletion in vegetarians? A cross-sectional (1)H-magnetic resonance spectroscopy ((1)H-MRS) study. Br J Nutr 111:1272-1274

Young E, Korszun A (2010) Sex, trauma, stress hormones and depression. Mol Psychiatry 15:23-28

Zhou X, Michael KD, Liu Y, Del Giovane C, Qin B, Cohen D, Gentile $\mathrm{S}$, Xie P (2014) Systematic review of management for treatmentresistant depression in adolescents. BMC Psychiatry 14:340

Zhu XH, Du F, Zhang N, Zhang Y, Lei H, Zhang X, Qiao H, Ugurbil K, Chen W (2009) Advanced in vivo heteronuclear MRS approaches for studying brain bioenergetics driven by mitochondria. Methods Mol Biol 489:317-357 